\title{
Impact of Enforcement and Co-Management on Compliance Behavior of Fishermen
}

\author{
Jamal Ali \\ College of Arts and Sciences, Universiti Utara Malaysia, 06010 Sintok, Kedah, Malaysia \\ Tel: 60-4-928-6782Ｅ-mail: jamalali@uum.edu.my \\ Hussin Abdullah \\ College of Arts and Sciences, Universiti Utara Malaysia, 06010 Sintok, Kedah, Malaysia \\ Tel: 60-4-928-3551Ｅ-mail: ahussin@uum.edu.my
}

This study was made possible through a research grant from the Economy and Environment Program for Southeast Asia (EEPSEA). Thanks to the EEPSEA panel of experts for their guidance and suggestions for the improvement of the study.

\begin{abstract}
The purpose of this paper is to examine the factors believed to affect compliance behavior with regard to the zoning regulation of 284 Peninsular Malaysian fishermen. Frequent violation of regulations will have an impact on the demand for protection, and therefore lead to greater expenditure on law enforcement. The theoretical models of compliance behavior tested include the basic deterrent model, which focuses on the certainty and severity of penalty as a key determinant of compliance, and models which integrate economic theory with theories of social psychology to account for legitimacy, deterrence and other motivations expected to influence an individuals' decisions on whether to comply. Policy makers who want to improve compliance face two choices: the first choice is whether to focus only on building staff capacity to detect and correct non-compliance; and the second choice is a combination of the strategies in building staff capacity and at the same time building commitment among fishermen so that they will comply with the regulations. The results of the empirical analysis provide evidence of the relationship between co-management strategies on the one hand, and types of fishermen on the other. These findings imply that co-management activities should be strengthened to complement the deterrent strategies in the management of fishery resources in Peninsular Malaysia.
\end{abstract}

Keywords: Co-management, Fishery, Fishermen, Compliance, Violation

\section{Introduction}

Over-fishing and declining marine fish landings, especially along the West Coast of Peninsular Malaysia are two important issues in Malaysia. According to the Department of Fisheries (DOF), Malaysia, this decline in coastal fisheries production is expected to continue as the maximum sustainable yield has been reached (DOF 1997). This is of great concern to economists, as the fisheries sector in 2000 contributed 1.6 percent to Gross Domestic Product (GDP) and employed 81,994 fishermen (DOF 2002).

Like in most countries, the fishery industry of Malaysia is an open-access resource, which means fishing is open to any new entrant. Even though the fishermen may be well aware of catching less fish today, they are also aware that any future catch may be large enough to make it worthwhile to 'invest in the stock'. They also know that any curtailment of their current catch simply results in an increased catch for someone else. As a result, fishermen may try to "harvest" what they can, when they can, and before anyone else.

With the introduction of more progressive and efficient fishing techniques, as has been witnessed over the past decade or so, the need for stock management policies has become more and more acute. New technology means that fishing is no longer limited to the captain's skills and the crew's strength. A fishing vessel can use directional sonar to help captains "see" shoals of fish and even distinguish between the species. Through the implementation of a Vessel Tracking and Monitoring System (VTMS), based on the Global Positioning System and Inmarsat satellite communications technology, fishing vessels can now lay their nets precisely where fish have schooled in the past. At the same time VTMS will allow the authorities to detect and identify the location of the fishing vessels (Malaysian Institute of Economic Research (MIER) 1999). 
The function of the existing regulatory institutions like the Department of Fishery (DOF) is to protect fish resources from over-exploitation by traditional and commercial fishermen. The DOF typically controls fishermen's activities through monitoring, surveillance, and enforcement under the Fisheries Act (1985). Policy makers who want to improve compliance face two choices: the first is whether to focus only on building staff capacity to detect and correct non-compliance, or the second choice, to adopt a combination of strategies in building staff capacity and at the same time building commitment among fishermen so that they will comply with regulations.

\section{Research Problem}

The fishing industry in Malaysia is characterized by a distinct dualism between the small-scale (traditional) and the large-scale commercial operators. Small-scale means fishing within five nautical miles from the shore along the coastline of their fishing villages. Most small-scale fishermen use long-tailed outboard-motored fishing vessels of less than 10 ton gross weight. The main fishing equipment used are push net, shrimp drift gillnet, and hook and line. The operations of the large-scale commercial fishermen, on the other hand, are carried out on a larger scale and are highly profit-motivated. Commercial fishermen use motored fishing vessels of over 10 gross Tonnes (GRT). The main fishing equipment for commercial fishermen are traws, purse seine, and other large gillnets. To reduce conflicts between the small-scale fishermen and the commercial fishermen, the Fisheries Authorities have established Management Zones (Fisheries Act 1985). Zoning is aimed at providing an equitable allocation of the fishery resources among the different sizes of fishing vessels and types of fishing equipment. The zoning system determines the allocation of fishing grounds, which is based on the types of fishing equipment, size of vessels, and ownership. Under the Fisheries Act (1985) of Malaysia the commercial fishermen can only operate in waters beyond 5 nautical miles $f$ the coastline.

The ban on commercial fishermen operating within five nautical miles of the shore (the area in which small-scale fishermen do most of their fishing) was imposed to prevent destructive gear from degrading the coastal fishing areas and tearing up stationary gear (such as stake nets and stationary traps). Conflicts among small-scale and commercial fishermen mostly occur when commercial trawlers stray into the prohibited zones. Numerous reports and personal interviews with fisheries officials and fishermen suggest that commercial fishermen persistently ignore the ban, creating smaller catches of fish for small-scale fishermen.

When the rate of non-compliance with regulations is thought to be significant, policymakers generally focus on increased deterrence, which in practice usually means greater enforcement effort as the only solution. However, effective monitoring and enforcement means higher expenditure and the government may not be able to bear such costs. Given the high costs of monitoring, a better understanding of the fishermen's motivation for compliance with the management arrangements is urgently needed.

The usual economic analysis of enforcement in fisheries, in common with that of the fishery management problem in general, assumes that fishermen act in all circumstances as self-interested rational agents. Given a choice of alternative actions, firms will seek to maximize profits and individuals will seek to maximize their utility in monetary terms, and the illegality of an action is only reflected in its expected cost. The shortcoming of this assumption is that not all fishermen may want to violate regulations, even though it is financially profitable to do so. The role of moral and social norms, as well as instrumental factors such as social pressure, in shaping individual behavior is examined extensively in the sociology and the social psychology literature. These factors, in addition to threats of sanctions, are recognized as important in determining individuals' compliance decisions.

\section{Literature Review}

A large number of survey studies has been conducted to test the economic model of criminal behavior as originally formulated by Becker (1968). Sutinen, Rieser \& Gauvin (1990) used the deterrent theory to conduct an econometric study of regulatory enforcement and compliance in the commercial inshore lobster fishery of Massachusetts in the United States. They set five testable hypotheses, namely: (1) lobstermen who were more income-dependent have a stronger conservation motive and were more likely to comply with conservation and management regulations; (2) lobstermen with more years in the fishery were more likely to perceive and appreciate the long-term benefits of conservation and management measures, and were more likely to comply with regulations; (3) younger lobstermen faced greater financial pressure and were more likely to violate regulations to realize short-term gains; (4) lobstermen with relatives in the fishery had a greater interest in the long-term health of the fishery and were less likely to violate regulations; and (5) frequent violators tended to remain in the fishery for short-term gains only.

The model used by these researchers assumed that violation rates were a function of probabilities of detection and conviction, level of economic gains from violation activities and variables reflecting the fishermen's commitment to the fishery. The data from a survey of people holding commercial inshore lobster licenses (lobstermen) for the year 1986 were estimated to be using ordinary least square (OLS), tobit and logit regression. The results indicated that 
lobstermen complied with the regulations even when illegal gains were so much larger than the expected penalties. Many of them referred to the need to "do the right thing," i.e. to obey a set of rules imposed by the authorities.

The first compliance study carried out in Malaysia was by Kuperan \& Sutinen (1998), who studied the compliance behavior of fishermen with zoning regulations in the Malaysian Fishery. In that study, they used both the Positive Theory (Deterrent Theory) and the Normative Theory (Social Influence and Cognitive Theory) to estimate a compliance model. Based on a sample of 318 trawler fishermen, Kuperan \& Sutinen included variables relating to social influence, behavioral norms and the legitimacy of regulations. They noted that, in practice, the costs of enforcing fisheries regulations resulted in relatively low probabilities of detection, but the penalties were not usually sufficiently high to produce a deterrent effect. Despite this, the authors observed that a high proportion of fishermen complied with regulations. This led them to look for other factors that explained individual compliance behavior. The researchers developed an extended model that, alongside monetary incentives, included variables such as "moral obligation" and "social influence". In their model, moral obligation included variables related to moral norms, as well as the perceived legitimacy of the regulator and the regulations.

Their study showed that income potential plays a major role in the compliance decisions of fishermen. When the difference in the catch-per-unit effort between the zones becomes more pronounced, the incentive for the trawlers to violate the zoning regulations increases. The researchers also found that moral development and social influences factors were statistically significant in explaining compliance behavior in the normative model. The normative perspective on compliance behavior, which emphasized the role of legitimacy of the enforcement institutions in securing compliance, was not significant.

Previous studies concerning compliance with fisheries regulations have followed two explanatory lines of argument. The first dealt with the positive theories (i.e. deterrent theory), i.e. the higher the probability of detection and the rate of fines imposed, the lower the rate of violations committed. The second line of explanation focused on normative theories, i.e. using factors that caused fishermen to become conscious of the fisheries regulations. Factors such as the fishermen's personal characteristics, their "psychological/attitudinal" orientations, and existing fishery policies were the focus of this line of enquiry. Age, experience, fishermen's income, household characteristics, their perceived attitudes toward the regulator and the regulations, moral values as well as their perception of other fishermen's compliance activity affected their own compliance with fishery regulations.

The operational variables that will be used in the present study were selected from the related theories and studies that have been reviewed. The model used is an extension of Kuperan \& Sutinen's (1998) work with certain modifications, especially the effect of co-management programs on compliance behavior.

\section{Theoretical Framework}

The main assumption in the economic analysis of criminal behavior is that the individual is a rational decision-maker who considers the costs and benefits of participation in illegal activities. In the present context, fishermen are assumed to subjectively weigh the potential gains and losses of committing a regulatory infraction. A fisherman's decision of whether to comply with regulations or not is modeled as a function of: (1) the probability of getting caught violating fishery regulations (PDETECT); (2) severity of the penalty (PENALTY); (3) illegal gains (IG); (4) a set of demographic and individual characteristics (EXPER, CONV, HP, SIZE, EXPEVA, AREA, FSIZE, $R E G, I N V, C O N V$ ); (5) involvement with co-management activities $(C O-M)$; and (6) a set of normative (non-economic) factors such as moral, social control and legitimacy. By incorporating the details of the fishery laws with the regulatory, economic and normative (non-economic) factors, a more complete assessment of the decision of the fishermen to violate the laws can be developed.

An individual's utility from illegal activity (rule violation) $U(V)$ can be written as a function of the anticipated monetary return under violation $Y_{V}$, the subjective probability of detection $p$, and of incurring an expected monetary penalty $F$, if caught and penalized, with the standard form

$$
U(V)=(1-p) U(Y)+p U\left(Y_{V}-F\right)
$$

In many cases it may be assumed that in addition to the imposition of a fine $F$, the value of the illegal income $Y_{V}$ will be forfeited if an individual is caught. Note that $Y_{V}$ is the income under violation and $Y_{N V}$ is the income under no violation. Then:

$$
U(N V)=U\left(Y_{N V}\right)
$$

Violation will occur if $U(V)>U(N V)$ and that $Y_{V}>Y_{N V}$.

Time spent on non-compliance activity is assumed to contribute directly toward fisherman's utility in terms of generating higher income $\left(Y_{V}\right)$. Income generated from the illegal activity is used to consume goods that contribute 
to utility. However, subjective probability of detection $p$, and an expected monetary penalty $F$, if caught and penalized will also affect utility from the non-compliance activity.

Within the standard economic framework of crime and punishment, the optimal remedy for non-compliance is

$$
\mathrm{F}^{*}=\frac{\text { monetary return under violation }}{\text { probability of detection }}=\frac{Y_{V}}{p(r)}
$$

where the optimal fine $\left(\mathrm{F}^{*}\right)$ is (at least) equal to the financial gain of non-compliance $\left(Y_{V}\right)$ divided by the probability of being detected and punished for the particular violation $(p(r))$, whereas $p(r)$ shows that the level of resources $r$ determines the probability of detection. For some fixed expected financial gain $\left(Y_{V}\right)$, the optimal fine will decline when the probability of detection $(p(r))$ increases.

In this study the focus is on an illegal act, i.e. violating zoning regulations. Since compliance simply represents the certain outcome $\mathrm{U}(\mathrm{NV})=\mathrm{U}\left(\mathrm{Y}_{\mathrm{NV}}\right)$ we can focus only on the decision to violate or not to violate the regulations. The individual's expected utility from violation depends the expected monetary gain $\left(Y_{i}\right)$, the perceived probability of detection $\left(p_{i}\right)$, and the expected size of the penalty if caught $\left(F_{i}\right)$. The violation decision by an individual fisherman $\left(V_{i}\right)$ related to the first three of these variables as mentioned in the deterrent theory can be written as

$$
\mathrm{V}_{\mathrm{i}}=\mathrm{f}\left(\mathrm{Y}_{\mathrm{i}}, \mathrm{p}_{\mathrm{i}}, \mathrm{F}_{\mathrm{i}}, \mathbf{X}_{\mathrm{i}}\right)
$$

where $\mathbf{X}_{\mathrm{i}}$ represents a vector of other variables including personal characteristics such as the individual's experience, size of the boat, fishing areas and involvement with co-management activities.

We adapt the model from Dowell, Goldfarb, and Griffith (1998) and Hatcher et al. (2000) who are proposed a good theoretical framework on an extended compliance model. In their theoretical utility framework, an individual's behavior is influenced by his own moral values, perception of legitimacy and social influences.

We can now re-write the supply of violations [4] to include index variables for moral obligation $(M)$, perceptions of legitimacy $(L)$, and social influences $(S)$. With this in mind we can write the individual's supply of violations function as

$$
\mathrm{V}_{i}=\mathrm{f}\left(\mathrm{Y}_{i}, \mathrm{p}_{i}, \mathrm{~F}_{i}, \mathrm{CO}-\mathrm{M}_{i}, \mathbf{M}_{\mathrm{i}}, \mathbf{L}_{\mathrm{i}}, \mathbf{S}_{\mathrm{i}}, \mathbf{X}_{\mathrm{i}}\right)
$$

for the initial form for estimation.

\section{Data}

\section{Data Sources}

Data for this study came from both primary and secondary sources. The nature of the study required primary data and information on co-management activities in the selected fishing areas. Data on compliance behavior were collected from primary sources using a structured questionnaire. The questionnaire was developed over a period of three months (from April to June 2001) during which time it was tested and retested an respondents in the study areas. Most of the items in the questionnaire came from Kuperan \& Sutinen (1998) and Hatcher, Jaffry, Thebaud \& Bennet (2000). A pilot study was carried out in June 2001 on a small diverse group of 40 fishermen to confirm the appropriateness of the questions in the questionnaire. After the pilot study, changes were made to the sequence and wordings of the questions to make them simpler. The actual survey was conducted between November 2001 and April 2002.

Secondary data necessary for the study were obtained from several sources. The Department of Fisheries and the Fisherman's Association were the two main sources of secondary sources. Visits to other statistics offices and district extension centers were also made to collect more detailed data required by the study. Examples of data collected from the secondary sources were the names of fishermen who had violated the regulations and the Department of Fisheries activities.

\section{Sampling Technique}

The unit of analysis in this study is the individual commercial fisherman in Peninsular Malaysia. As for drift-net fishermen, the questionnaire was only given to fishermen who had fishing vessels weighing more than 20 GRT, and who were required to follow zoning regulations. The questionnaire was administered personally to 284 fishermen who were chosen using a disproportionate stratified random sampling. By using stratified random sampling, more information was collected from each group of fishermen. Firstly, we stratified the fisherman population into three groups according to the main fishing equipment used in their fishing activity - trawl nets, purse seine nets and drift nets. Then, a sample of members from each stratum was drawn by using simple random sampling. 
The survey was conducted in selected fishing areas in Peninsular Malaysia where these three types of fishing equipment were used, namely, Perlis, Kedah (North Kedah and South Kedah), Pulau Pinang, Perak (Krian), Selangor (Central Selangor and South Selangor), Johor (Mersing), Pahang (Kuantan), Terengganu (Kuala Terengganu) and Kelantan (Pasir Putih, Bachok, Kota Bahru and Tumpat). Two states (Melaka and Negeri Sembilan) were excluded from this study because they have no trawler fishermen.

Table 1 shows the sample size and the population of licensed fishermen with inboard-powered vessels of more than 20 Gross Tonnage (GRT) or those using trawl nets and purse seine nets as their main fishing equipment. The names and addresses of the fishermen surveyed were obtained from the records of DOF (Department of Fisheries) and the Fishermen's Associations. All data were collected through face-to-face interviews with the skippers of the vessels. From the full sample of 284, 51\% (146) were trawler fishermen, $27 \%$ (77) purse seine fishermen, and 22\% (61) drift net fishermen.

\section{STATistical ANALYSIS}

The primary data were analyzed by using SPSS (Statistical Package for Social Sciences) and STATA. The probability of detection $\left(p_{\mathrm{i}}\right)$ and the probability of violation $\left(V_{i}\right)$ models were estimated using logit regression. The logit model extends the principles of the generalized linear models to handle the case of dichotomous dependent variables. Logit differs from linear regression in that it estimates the parameters of the model using the maximum likelihood method instead of the ordinary least squares method, and the function used in the logit model is the natural log of the odds ratio (Ramanathan 1995).

\section{ANALYSIS AND INTERPRETATION OF RESULTS}

This section reports the findings of the empirical analysis, starting with a descriptive analysis, followed by the result the hypothesis testing. For hypothesis testing on the violation decision model, the logit regression technique was used.

\section{Descriptive Statistical Analysis}

\section{Comparative Analysis}

Descriptive findings for the respondents' compliance behavior are summarized in Table 2. We used comparative analysis to provide an insight into four characteristics of the respondents (income, experience, size of the boat, and expenditure on evasion activity) between violators and non-violators, and among different types of fishermen (trawlers, purse seines, and drift net fishermen). From the results, it may be seen that the mean of the co-management index is higher for non-violators than violators. The mean of the co-management index for non-violators (trawler fishermen) is 2.1 , while for violators it is only 1.2. The result suggests that fishermen who are more actively involved in co-management activities have more tendencies to comply with the fishery regulations. The same situation occurs with purse seine versus drift net fishermen, where the mean of the co-management index $(C O-M)$ for non-violators (purse seiner fishermen and drift net fishermen) is 2.3, and the mean of the co-management index for violators (purse seine fishermen) is 2.2. However, the co-management index for violators (drift net fishermen) is only 0.8 .

Fishermen's income was defined in the survey as the sum of the monthly cash income from fishing activities. As shown in Table 2, the mean income (INCOME) of violators was higher than that of non-violators. For example, the mean income for trawlers who violated the regulations (violators) is RM1,598 per month, while the mean income for non-violator trawlers (complier) is only RM1,102 per month. In other words, the result suggests that income might be one of the factors that influence fishermen to violate the regulations.

The result also shows that mean expenditure on evasion activity (EXPEVA) by non-violators is higher than that of violators for trawler and purse seine fishermen. For trawler fishermen, non-violators spent about RM2,194 per month for evasion activity, compared to violators, who spent only RM1,349 per month. The same characteristics were found for purse seine fishermen. Non-violators (purse seine fishermen) spent about RM2,364 per month for evasion activity, compared to violators, who spent only RM1,465 per month. These descriptive findings indicate that fishermen who spend more on evasion activity are more likely not to get caught by enforcement officers.

Estimation Results

The individual's supply of violations shown in equation [5] is specified as

$$
\mathrm{V}_{i}=\mathrm{f}\left(\mathrm{Y}_{i}, \mathrm{p}_{i}, \mathrm{~F}_{i}, \mathrm{CO}-\mathrm{M}_{i}, \mathbf{M}_{\mathrm{i}}, \mathbf{L}_{\mathbf{i}}, \mathbf{S}_{\mathbf{i}}, \mathbf{X}_{\mathrm{i}}\right) \text {. }
$$

where $V_{i}$ is the self-reported violation rate, $p_{i}$ is the perceived probability of detection, $F_{i}$ is the expected size of the penalty if caught $\left(F_{i}\right)$, and CO-M $\mathbf{M}_{i}$ is the level of involvement with co-management activities. $\mathbf{M}_{i}, \mathbf{L}_{i}$, and $\mathbf{S}_{i}$ are 
vectors of variables measuring moral obligation to comply, perceptions of regulatory legitimacy, and social influence. While $\mathbf{X}_{i}$ is a vector of variables to describe the characteristics of the fishermen and their vessels.

\section{Use of the Logit Estimation on Probability of Violation.}

$\mathrm{H}_{\mathrm{A}}$ : The four independent variables, namely, the economic factors, demographic factors, non-economic factors (normative factors) and co-management index will significantly explain the variance in the probability of violation by an individual fisherman.

Table 3 presents the logit estimation of the probability of violation. To evaluate the goodness of fit, the predictive ability of the model is calculated. It is found that the percentage correctly predicted is $83 \%$. Thus, it is concluded that the model estimated has satisfactory predictive ability. The Pseudo $\mathrm{R}^{2}(0.44)$ is reasonable and the computed value of the Wald test statistics (87.74) is much larger than the critical value of the chi-squared statistics at the 1 percent level. This means that the empirical model is significant in explaining the probability of violation by fishermen.

Of the 284 observations, only 146 observations could be used in this regression because of the problem of missing observations (138 observations), representing an attrition rate of $48.6 \%$, which is high. Of the 146 usable observations, 76 were violators $(47.95 \%)$ and 70 non-violators $(52.05 \%)$.

From Table 3, the estimated probability of violation (VIOLATE) is found to be negatively related to perceived probability of detection (DETECT), co-management index $(C O-M)$. VIOLATE is positively related with the power of the vessel $(H P)$, illegal gain (IG), type of fishermen (DTYPEl) and self-regulation $(R E G)$, all being significant at the $5 \%$ level.

The finding that the probability of violation (VIOLATE) is negatively related to the probability of detection (DETECT) is expected - it follows from the theoretical predictions made earlier (the relationship is significant at the $5 \%$ level). A negative sign implies that the higher the perceived probability of detection, the lower the probability of a violation.

The co-management index $C O-M$ is found to have an effect on the probability of violation. The higher the co-management index, the lower the probability of violation. The inverse relationship between the probability of violation and the co-management variable $C O-M$ suggests that fishermen who are more involved in the design and implementation of the management system are less likely to violate zoning regulations. There appears to be a positive relationship between the horsepower of fishermen's engines $(H P)$ and the probability of violation. Fishermen with more powerful engines are more likely to violate regulations because of the potential for them to get away very quickly.

Illegal gain $(I G)$ is an influential factor in the violation models, as implied by the positive coefficient of $I G$. As expected from the theory of deterrence, the size of illegal gains does influence fishermen's tendencies to violate the regulations - the bigger the gain the higher is the probability of violation.

Compared to those who use "purse seine nets and others", fishermen who use "trawlers" (DTYPE 1) are found to have a higher probability of violation. This positive relationship is significant at the $5 \%$ level.

Self-regulation $(R E G)$ is found to have an unexpected positive relationship with the probability of violation. The positive sign for the $R E G$ variable implies that a fisherman who says there is some form of agreement among fishermen in the fishing areas is found to have a higher probability of violation. This may appear puzzling but it could be because the fishermen know about the agreements but do not care about them, and still violate the regulations.

\section{Discussion and Conclusions}

The purpose of this research is to examine the determinants of fishermen's behavior with a focus on the impact of traditional monitoring and enforcement practices, and co-management strategies. Our results provide some insights for public policy making. The basic finding that the probability of detection and the involvement with co-management activities are negatively related with violation decisions implies that fishery policymakers can do a number of things for an effective strategy to improve regulatory compliance in fisheries.

Firstly, a higher probability of detection and penalty from enforcement activities will discourage people from committing illegal activities. Improving the enforcement process and its intensity can do this. As noted above, in almost any group of individuals subjected to regulations there is a core subgroup of chronic violators motivated by high returns (illegal gains) from their actions. Enforcement institutions are very well established in Malaysia, so what is needed is to implement enforcement more effectively. However, this policy, which depends on central management, is not very economical because of the high costs of monitoring and enforcement. For example, the 
number of staff and patrol boats for law enforcement is limited in relation to the coastal length of $1,640 \mathrm{~km}$ and the huge number of fishing vessels (i.e. 18,846 fishing vessels in 2001) operating various types of fishing gears. Besides that, the construction and operating costs of patrol boats are quite high. It is reported that enforcement institutions such as the Department of Fisheries allocate quite a big budget for monitoring activities, yet it is still inadequate. When the capacity of the enforcement resources is limited, many violators will escape detection. The prospect of a hefty fine clearly provides an incentive to engage in such evading activities. As the regression of probability of detection model has shown, as expenditure on evading activities increases, the fisherman's perception of the probability of detections decreases. The findings show that even though improving the probability of detection and increasing penalty severity on the violators can influence compliance behavior, factors such as budget constraint and spending on evading activities can make this strategy to be limited in improving regulatory compliance. However, since improving the probability of detection and increasing penalty severity on the violators can influence compliance behavior, policy makers still should use this technique in addition to other alternative techniques such as the co-management programs.

Secondly, the significance of the amount of illegal gain $(I G)$ in the decision to violate, poses some serious problems to policymakers. A large fine with a small probability of being detected may result in the optimal fine being lower than the offender's illegal gain. So, there is more incentive for fishermen to violate the regulations to get benefits from the illegal activity. This action follows the theory of compliance from economic perspectives. From the perspective of policy design, a given target level of compliance can be achieved by increasing the magnitude of the fines on these violators.

Thirdly, we also find that trawler fishermen are more likely to violate zoning regulations compared to other types of fishermen. Thus if the regulator's objective is to monitor fishermen's activities where it is more likely to observe non-compliance, then, in order to make the most of its limited resources, enforcement activities should concentrate more on monitoring the trawler fishermen. The argument is a simple one. When we know the groups that frequently violate the regulations, the least costly way to achieve a given expected compliance is to use enforcement resources on this group of fishermen. The Department of Fisheries (DOF) can control the number of fishermen using trawl nets as their fishing equipment. No more licenses should be issued to the new fishing vessels that want to use trawl nets. Only fishermen who have licenses for this type of fishing equipment can apply for an annual extension of their fishing licenses. DOF can even set a policy that fishing licenses are non-transferable to other operators. When a fisherman dies, the normal practice is that his license is transferred to his children. We suggest that DOF should make it mandatory that the fisherman's children change their fishing equipment from trawl nets to drift nets or purse seine nets. Hopefully, this policy might be able to control the number of fishermen using trawl nets. .

Lastly, we find that fishermen who are more involved in the co-management activity are more likely to comply with zoning regulations. This study shows that non-monetary factors such as the co-management approach can improve compliance decision. Instead of depending on monitoring and enforcement, application of co-management strategies in the fishery industry can be seen as a complement to the normal practice, which depends on deterrent strategies. The significance of the co-management variable in the decision to violate posits some good new ideas for policymakers. The application of co-management needs co-operative participation among the fishermen, as resource users, and stakeholders, such as the tourism industry, non-government organizations, academicians, boat owners, fish traders and the government. The government makes regulations based on scientific information, plus local knowledge of the status of the resources, while the users of the fishery resources, recognizing the long-term benefits of good management to them, follow and enforce better management practices.

\section{References}

Becker, G. S. (1968). Crime and punishment: An economic approach. Journal of Political Economy, 76 (2): 169-217.

Department of Fisheries (DOF). Annual fisheries statistics, 1997-2002. Department of Fisheries, Ministry of Agriculture, Malaysia.

Dowell, R. S., Goldfarb, R. S. \& Griffith, W. B. (1998). Economic man as a moral individual. Economic Inquiry, 36: 645-53.

Ehrlich, I. (1973). Participation in illegitimate activities: A theoretical and empirical investigation. Journal of Political Economy, 81: 521-64.

Hatcher, A., Jaffry, S., Thebaud, O.\& Bennett, E. (2000). Normative and social influences affecting compliance with fishery regulations. Land Economics, 76 (3): 448-461. 
Kuperan, K. \& Sutinen, J.G. (1998). Blue water crime: Deterrence, legitimacy, and compliance in fisheries. Law and Society Review, 32 (2): 309-338.

Malaysian Institute of Economic Research (MIER) (1999). Fisheries Development Study in Malaysia. Unpublished Interim Report submitted to Economic Planning Unit, Prime Minister Department.

Pomeroy R. S., Katon, B. \& Harkes, I. (2001). Conditions affecting the success of fisheries co-management: lessons from Asia. Marine Policy, 25: 197-208.

Ramanathan, Ramu (1995). Introductory Econometrics: With Applications (3 ${ }^{\text {rd }}$ Ed.). Forth Worth: The Dryden Press.

Sutinen, J. G., Rieser, A. \& Gauvin, J. R. (1990). Measuring and Explaining Noncompliance in Federal Managed Fisheries. Ocean Development and International Law, 21:335-72.

Table 1. Sample size for trawler, purse seine and gill net fishermen

\begin{tabular}{lccc}
\hline \multicolumn{1}{c}{ Gear Groups } & $\begin{array}{c}\text { Number of respondents } \\
\text { interviewed (sample) }\end{array}$ & $\begin{array}{c}\text { Number of licensed fishing } \\
\text { vessels } \\
\text { (Population) }\end{array}$ & $\begin{array}{c}\text { Sample as a percent of population } \\
\text { Trawl nets }\end{array}$ \\
Purse seine nets & $146(51.4 \%)$ & 4,609 & $3.2 \%$ \\
Drift nets & $77(27.1 \%)$ & 748 & $10.3 \%$ \\
Total & $61(21.5 \%)$ & 400 & $15.3 \%$ \\
\hline
\end{tabular}

Table 2. Descriptive Statistics: Comparative analysis between groups of fishermen

\begin{tabular}{|c|c|c|c|c|c|c|c|}
\hline Fishing Equipment & Violate & Variables & $\mathrm{N}$ & Minimum & Maximum & Mean & Std. Deviation \\
\hline \multirow[t]{9}{*}{ 1.Trawler } & \multirow[t]{4}{*}{ No } & Experience & 58 & 4 & 45 & 22.1 & 11.61 \\
\hline & & Co-management & 58 & 0 & 7 & 2.1 & 2.1 \\
\hline & & Expeva & 43 & 0 & 11000 & 2194 & 2925 \\
\hline & & Income & 58 & 300 & 5000 & 1102 & 1053 \\
\hline & \multirow[t]{5}{*}{ Yes } & Experience & 88 & 1 & 58 & 21.0 & 12.8 \\
\hline & & Co-management & 88 & 0 & 6 & 1.2 & 1.8 \\
\hline & & Expeva & 66 & 0 & 15000 & 1349 & 2652 \\
\hline & & Income & 88 & 260 & 6000 & 1599 & 1409 \\
\hline & & Compound & 33 & 300 & 2800 & 1030 & 571 \\
\hline \multirow[t]{9}{*}{ 2. Purse seine } & \multirow[t]{4}{*}{ No } & Experience & 48 & 1 & 55 & 24.6 & 13.9 \\
\hline & & Co-management & 48 & 0 & 7 & 2.3 & 1.6 \\
\hline & & Expeva & 22 & 0 & 20000 & 2364 & 5380 \\
\hline & & Income & 47 & 300 & 10000 & 1083 & 1454 \\
\hline & \multirow[t]{5}{*}{ Yes } & Experience & 29 & 2 & 53 & 19.3 & 14.3 \\
\hline & & Co-management & 29 & 0 & 8 & 2.2 & 1.9 \\
\hline & & Expeva & 23 & 0 & 20000 & 1466 & 4142 \\
\hline & & Income & 29 & 300 & 5000 & 1124 & 864 \\
\hline & & Compound & 16 & 300 & 3000 & 775 & 734 \\
\hline \multirow[t]{8}{*}{ 3. Drift net } & \multirow[t]{4}{*}{ No } & Experience & 55 & 1 & 41 & 21.7 & 11.8 \\
\hline & & Co-management & 55 & 0 & 8 & 2.3 & 2.8 \\
\hline & & Expeva & 41 & 0 & 6000 & 1576 & 1386 \\
\hline & & Income & 55 & 300 & 5000 & 1156 & 930 \\
\hline & \multirow[t]{4}{*}{ Yes } & Experience & 6 & 4 & 35 & 23.3 & 14.1 \\
\hline & & Co-management & 6 & 0 & 2 & .8 & .8 \\
\hline & & Expeva & 2 & 100 & 3000 & 1550 & 2051 \\
\hline & & Income & 6 & 500 & 3000 & 1433 & 1025 \\
\hline
\end{tabular}


Table 3. Logit Estimation of the Probability of Violation

\begin{tabular}{lccc}
\hline Variables & Expected Sign & Estimated Coefficients & t-statistic \\
\hline MORAL & - & -0.066 & -0.477 \\
LEGITIMATE & - & -0.002 & -0.012 \\
SOCIAL & - & -0.029 & -0.184 \\
CO-M & - & -0.634 & $-2.298^{* *}$ \\
PDETECT & - & -2.333 & $-2.771^{* *}$ \\
EXPER & - & 0.001 & 0.735 \\
HP & + & 0.009 & $0.05^{* *}$ \\
EXPEVA & + & -0.001 & -1.056 \\
IG & + & 0.004 & $2.004^{* *}$ \\
INC & + & 0.004 & 1.085 \\
DTYPE 1 & $+/-$ & 3.865 & $3.074^{* *}$ \\
DTYPE 2 & $+/-$ & 1.935 & 1.38 \\
REG & - & 3.107 & $2.013^{* *}$ \\
PENALTY & - & -0.127 & -0.183 \\
OWN & - & -1.185 & -1.397 \\
CONSTANT & + & 0.186 & 0.057 \\
\hline
\end{tabular}

Notes:

1. $\quad$ Log likelihood $=-56.35$; Wald Chi-square (D.F.) $=87.74$; Pseudo's $\mathrm{R}^{2}=0.44$; and Percentage of Correct Predictions $=83 \%$.

2. $* * *, * *, *$ Indicate that the variable is significant at the $1 \%, 5 \%$ and $10 \%$ levels respectively. 